\title{
Inhibitory Effect of Jing-Fang Powder n-Butanol Extract and Its Isolated Fraction D on Lipopolysaccharide-Induced Inflammation in RAW264.7 Cells
}

\author{
Zhili Rao, ${ }^{1}$ Haijuan Cao, ${ }^{1}$ Boyu Shi, Xiaobo Liu, Jie Luo, and Nan Zeng \\ Department of Pharmacology, College of Pharmacy, Chengdu University of TCM, Chengdu City, Sichuan Province, Chengdu, \\ PR China
}

Received December 22, 2018; accepted April 16, 2019

\begin{abstract}
The Jing-Fang powder n-butanol extract (JFNE) has antiinflammatory properties; however, its active ingredient remains unknown. In addition, the mechanism by which JFNE exerts its anti-inflammatory effects on lipopolysaccharide (LPS)-induced inflammation in RAW264.7 cells is yet to be explored. In this study, JFNE was isolated by chromatography to obtain fraction D. We found that pretreatment of LPS-induced RAW264.7 cells with JFNE and fraction D for 3 hours significantly reduced the levels of nitric oxide (NO), interleukin (IL)-1 $\beta$, and tumor necrosis factor- $\alpha$ (TNF- $\alpha$ ) in the supernatant of cell cultures, and fraction $D$ could also reduce the level of IL-6. In addition, JFNE and fraction D significantly reduced the mRNA expression of inducible NO synthase (iNOS), IL-6, IL-1 $\beta$, and TNF- $\alpha$. JFNE and fraction D significantly inhibited the phosphorylation
\end{abstract}

of proteins and mRNA expression levels of phosphoinositide 3-kinase (PI3K) and protein kinase B (PKB/AKT). Moreover, JFNE and fraction D significantly decreased the mRNA expression of iNOS, v-rel reticuloendotheliosis viral oncogene homo$\log A(R E L A)$, and nuclear factor of $\kappa$ light polypeptide gene enhancer in B cells 1 (NF- $\kappa$ B1), whereas an increase in the mRNA expression of conserved helix-loop-helix ubiquitous kinase (CHUK) was observed. In addition, JFNE and fraction $D$ downregulated the protein expression of iNOS, nuclear factor$\kappa \mathrm{B}(\mathrm{NF}-\kappa \mathrm{B})(\mathrm{p} 50)$, and phosphorylated NF- $\kappa \mathrm{B}$ (p65). These results show that JFNE and its isolated fraction D exert specific antiinflammation properties in LPS-stimulated RAW264.7 cells that are regulated by inhibition of the PI3K/Akt and NF- $\kappa \mathrm{B}$ signaling pathways.

\section{Introduction}

Schizonepeta tenuifolia Briq. and Saposhnikovia divaricata (Turcz.) Schischk. are two traditional Chinese medicines. Jing-Fang powder consists of the two herbs $(w / w=1: 1)$ and is typically used to treat exterior syndrome caused by exopathy, measles, and skin pruritus caused by rubella and eczema, and to prevent and treat allergic inflammatory diseases such as bronchitis and allergic rhinitis (Yu et al., 2013; Zhe et al., 2013; Changtian et al., 2016). Recent studies show that the essential oils and decoctions prepared from Jing-Fang powder have anti-inflammatory and anti-allergic properties. JingFang powder n-butanol extract (JFNE) has also been shown to be anti-inflammatory (Liu et al., 2007; Yu et al., 2013). Macrophages play an important role in maintaining cellular homeostasis, by enhancing the immune response during infection (Zhu et al., 2015). The M1 macrophage phenotype

This work was supported by the National Nature Science Foundation of China [81473399, J1310034-09] and Department of Pharmacology, Sichuan Provincial Science and Technology, Sichuan Province Youth Science and Technology Innovation Team [2014TD0007].

${ }^{1}$ Z.R. and H.C. contributed equally to this work.

https://doi.org/10.1124/jpet.118.255893. is induced by lipopolysaccharide (LPS) and proinflammatory Th1 cytokines such as interferon- $\gamma$. When macrophages are exposed to LPS, they induce significant phenotypic changes, which are characterized by the production of proinflammatory cytokines, including interleukin (IL)-1 $\beta$, IL-6, IL-12, tumor necrosis factor- $\alpha$ (TNF- $\alpha$ ), and inducible nitric oxide (NO) synthase (iNOS) (Johnston et al., 2012; Van Dyken and Locksley, 2013). Conversely, the released cytokines are capable of recruiting adaptive immune cells (such as T-lymphocytes) to neutralize phagocytosed pathogens by producing oxygen and nitrogen free radicals and secreting a series of inflammatory cytokines, which amplify the Th1 immune response to maintain and promote the inflammatory response (Nathan and Shiloh, 2000; Routray and Ali, 2016). The inflammatory mediators secreted by macrophages induce neutrophil migration to the site of injury, enhancing tissue damage (Takemura et al., 2005; Matthay et al., 2012). The phosphoinositide 3-kinase (PI3K) family plays an important role in transducing intracellular cell signals, and in the pathogenesis of inflammation, obesity, tumors, and immune-mediated diseases (Burke and Williams, 2015). AKT is a key protein in the AGC kinase family, which is involved in multiple cellular signaling pathways.

ABBREVIATIONS: AKT, protein kinase B; CHUK, conserved helix-loop-helix ubiquitous kinase; DMEM, Dulbecco's modified Eagle's medium; DMSO, dimethylsulfoxide; IL, interleukin; iNOS, inducible NO synthase; JFNE, Jing-Fang powder n-butanol extract; LC-MS, liquid chromatography-mass spectrometry; LPS, lipopolysaccharide; NF- $\kappa \mathrm{B}$, nuclear factor- $\kappa \mathrm{B}$; NO, nitric oxide; PI3K, phosphoinositide 3-kinase; RELA, v- rel reticuloendotheliosis viral oncogene homolog A; TNF- $\alpha$, tumor necrosis factor- $\alpha$. 
AKT a downstream target of PI3K, can be activated by PI3K phosphorylation (Brown and Banerji, 2017). After induction of the PI3K/Akt pathway, phosphorylated Akt activates nuclear factor $-\kappa \mathrm{B}(\mathrm{NF}-\kappa \mathrm{B})$ by enhancing the phosphorylation and degradation of the inhibitor of nuclear factor kappa-B kinase (IKK) (Shi et al., 2016). NF- $\kappa$ B regulates the expression of thousands of important biologic genes, which are necessary for multiple cellular functions. Recent studies demonstrated that the NF- $\kappa \mathrm{B}$ subunit plays an important role in controlling inflammation (Nguyen et al., 2014). The activation of NF- $\kappa \mathrm{B}$ may increase the levels of proinflammatory cytokines (such as TNF- $\alpha$, IL-6, and IL-1 $\beta$ ), chemokines, and adhesion molecules to enhance the inflammatory response. The expression of enzymes regulated by NF- $\kappa \mathrm{B}$, such as iNOS and cyclo-oxygenase-2, influences the chemotaxis of large numbers of inflammatory cells, such as neutrophils that infiltrate the tissue and aggregate at the site of inflammation (Zhang et al., 2017).

In this study, LPS-induced RAW264.7 cells were used to observe the anti-inflammatory effects of JFNE and its isolated fraction $\mathrm{D}$ in vitro, and to determine whether the antiinflammatory effects of JFNE and fraction $\mathrm{D}$ are regulated by the activation of PI3K/Akt and NF- $\kappa \mathrm{B}$ signaling pathways that control the release of inflammatory cytokines.

\section{Materials and Methods}

Preparation and Separation of JFNE. S. tenuifolia and S. divaricate (Lot: 160901, 160902; Taiji Pharmacy, Chengdu, China) were weighed $(3000 \mathrm{~g})$, and a 1:1 ratio was used. The decoction with essential oil was collected and concentrated for extraction with petroleum ether, ethyl acetate, and n-butanol sequentially to obtain JFNE. JFNE (100 g) was separated by silica gel column chromatography with a mobile phase composed of ethyl acetate:methanol (3:1) and eluted. The eluate was evaporated under reduced pressure to obtain $17.74 \mathrm{~g}$ fraction D. JFNE and fraction D were dissolved in dimethylsulfoxide (DMSO), and 0.25\% DMSO was used as the vehicle control during drug administration.

Experimental Cell Culture. RAW264.7 cells were purchased from the Shanghai Cell Bank of the Chinese Academy of Sciences and cultured in complete Dulbecco's modified Eagle's medium (DMEM) containing $10 \%$ fetal bovine serum in an incubator at $37^{\circ} \mathrm{C}$ and $5 \% \mathrm{CO}_{2}$.

Determination of the Effect of Test Drugs on Cell Viability by MTT Assay. RAW264.7 cells $\left(4 \times 10^{4}\right.$ cells $\left./ \mathrm{ml}\right)$ were uniformly seeded in a 96 -well cell culture plate and incubated for 12 hours; after culturing with each drug for 6 hours, $100 \mu \mathrm{l}$ MTT (Cell Proliferation and Cytotoxicity Assay Kit; Beyotime, Chengdu, China) solution (100 $\mu \mathrm{l}$ medium containing $10 \mu \mathrm{l}$ MTT) was added to each well and cultured for 3 hours. The supernatant was carefully removed, and $100 \mu \mathrm{l}$ DMSO was added. The optical density value of each well was detected at $570 \mathrm{~nm}$.

LPS Stimulation and Detection of NO, IL-6, IL-1 $\beta$, and TNF$\boldsymbol{\alpha}$ in Culture Supernatant. RAW264.7 cells were seeded in six-well plates at $5 \times 10^{5}$ cells $/ \mathrm{ml}$ and cultured for 24 hours. The cultured cells were divided into seven groups including control, LPS $(1 \mu \mathrm{g} / \mathrm{ml})$, LPS + DMSO, LPS + JFNE $(0.5,0.25 \mathrm{mg} / \mathrm{ml})$, and LPS + fraction D $(0.5,0.25 \mathrm{mg} / \mathrm{ml})$. Each group was pretreated with the corresponding concentration of each drug for 3 hours; the blank control group and the LPS-treated group contained an equal volume of DMEM; and the DMSO control group contained the same volume of DMEM with $0.25 \%$ DMSO. There were four technical replicates per group. After 3 hours of treatment, the culture solution was aspirated, with the exception of the blank control group in which DMEM was added. DMEM $(1.5 \mathrm{ml})$ containing $1 \mu \mathrm{g} / \mathrm{ml}$ LPS was added to the other wells for 12 hours. The cell culture supernatant was collected, and the content of nitric oxide (NO) was determined using a Total Nitric Oxide Assay Kit (Beyotime). The levels of IL-6, IL- $1 \beta$, and TNF- $\alpha$ in the cell culture supernatant were determined by enzyme-linked immunosorbent assay (ExCell Biotechnology, Shanghai, China), according to the manufacturer's instructions.

Determination of mRNA Expression via ReverseTranscription Polymerase Chain Reaction. Total cellular RNA was extracted from RAW 264.7 cells using the AxyPrep Multi-Source Total RNA Miniprep Kit, according to the manufacturer's instructions (Axygen), and cDNA was synthesized from total RNA using the FastQuant RT kit (Tiangen, Beijing, China). The amplification reaction was carried out in a 96-well reaction plate (Bio-Rad, Chengdu, China) in a reaction volume of $20 \mu$ l. The primer sequences used in this study are as follows: $\beta$-actin-F: 5'-ACAGCTGAGAGGGAAATCGTG-3', $\beta$-actin-R: 5' - AGAGGTCTTTACGGATGTCAACG-3'; conserved helixloop-helix ubiquitous kinase (CHUK)-F: 5'-TCTACTCCCCAAGGTGGAAG-3', CHUK-R: 5'-GTCAGAGGATGTTCACGGTC-3'; IL-1 $\beta$-F: $5^{\prime}$ CAACTGCACTACAGGCTCCG-3', IL-1 $\beta$-R: $5^{\prime}$-GTGGGTGTGCCGTCTTTCAT-3'; IL-6-F: 5'-AGACAAAGCCAGAGTCCTTCAG-3', IL-6-R: 5'AGGAGAGCATTGGAAATTGGG-3'; iNOS-F: 5'-ACCATGAGGCTGAAATCCCA-3', iNOS-R: 5'-TCCACAACTCGCTCCAAGAT-3'; NF- $\kappa$ B1-F: 5'-ATGTAGTTGCCACGCACAGA-3', NF- $\kappa$ B1-R: 5' - GGGGACAGCGACACCTTTTA-3'; PI3K-F: 5'-GATGAGGATTTGCCCCACCA-3', PI3K-R: 5'-TTGACTTCGCCGTCTACCAC-3'; AKT-F: 5'-CCGAGGATGCCAAGGAGATCA-3', AKT-R: 5'-GTAGGAGAACTGGGGGAAGTGC-3'; TNF$\alpha$-F: 5' - ACGGCATGGATCTCAAAGACA-3', TNF- $\alpha$-R: 5'-GTGAGGAGCACGTAGTCGG-3'; v- rel reticuloendotheliosis viral oncogene homolog A (RELA)-F: 5'-TATCTCGCTTTCGGAGGTGC-3', RELA-R: 5'-GCGTGGAGGAAGACACTTGA-3'. The fold change in target genes between the control and treatment groups was normalized with $\beta$-actin expression levels. The changes in gene expression were calculated using $2^{-\Delta \Delta \mathrm{Ct}}$.

Analysis of the Effects of JFNE and Fraction D on NF- $\kappa$ B Signaling Pathway by SN50. To explore the effects of JFNE and fraction D on NF- $\kappa \mathrm{B}$ signaling, $40 \mu \mathrm{M}$ SN50, an inhibitor of NF- $\kappa \mathrm{B}$ signaling, was added 1 hour before treatment with JFNE and fraction $\mathrm{D}$; the NO content in the cell culture supernatant was determined by Griess method; and the protein levels of IL- $1 \beta$ and TNF- $\alpha$ were determined by enzyme-linked immunosorbent assay.

Western Blotting. After treatment with JFNE or fraction D for 3 hours, and LPS stimulation for 12 hours, $180 \mu \mathrm{l}$ radioimmunoprecipitation assay lysate buffer (Beyotime) containing $1 \mathrm{mM}$ phenylmethylsulfonyl fluoride (Med Chem Express) was added to each well to extract the total protein in the cells. The total protein concentration of each sample was determined using the bicinchoninic acid kit (Beyotime), and all samples were adjusted to the same concentration. The protein samples were mixed with a $5 \times$ loading buffer and denatured in at $95^{\circ} \mathrm{C}$. The proteins were separated by SDS-PAGE ( $8 \%$ or $12 \%$ ) and electrophoretically transferred onto polyvinylidene fluoride membranes. The membranes were labeled with PI3K p85 (19H8) rabbit mAb, phospho-Akt (Ser473) (D9E) XP rabbit mAb, Akt (pan) (C67E7) rabbit mAb, $\beta$-actin (13E5) rabbit mAb, NF- $\kappa \mathrm{B} 1$ p105/p50 (D4P4D) rabbit $\mathrm{mAb}(1: 1000$, catalogue 4257, 4060, 4691, 4970, 13586; Cell Signaling Technology), anti-NF- $\kappa$ B p65 (phospho S536) rabbit pAb, anti-iNOS/NO synthase 2 rabbit $\mathrm{pAb}$, anti-NF- $\kappa \mathrm{B}$ p 65 rabbit $\mathrm{pAb}$, and anti-glyceraldehyde-3-phosphate dehydrogenase rabbit pAb (1:1000, catalogue GB11142, GB11119, GB11142, GB11002; Servicebio), overnight at $4^{\circ} \mathrm{C}$, and then incubated with anti-rabbit IgG horseradish peroxidase-linked secondary antibody (1:2000, catalogue 7074; Cell Signaling Technology) at $37^{\circ} \mathrm{C}$ for 1 hour. Antibody detection was performed using a ChemiDoc $\mathrm{XRS}^{+}$(Bio-Rad, Hercules, CA) image analysis system.

Analysis of Main Components of Fraction D by Liquid Chromatography-Mass Spectrometry. Liquid chromatography-mass spectrometry (LC-MS) (UltiMate 3000 LC, Orbitrap Elite; Thermo Scientific) was performed using Waters ACQUITY UPLC HSS T3 $(2.1 \mathrm{~mm} \times 100 \mathrm{~mm} 1.8-\mu \mathrm{m}$ columns$)$, and the chromatographic separation conditions were as follows: column temperature, $40^{\circ} \mathrm{C}$; flow 
rate, $0.3 \mathrm{ml} / \mathrm{min}$; mobile phase $\mathrm{A}$, water $+0.1 \%$ formic acid; mobile phase $\mathrm{B}$, acetonitrile $+0.1 \%$ formic acid; injection volume, $4 \mu \mathrm{l}$; automatic injector temperature, $4^{\circ} \mathrm{C}$; and gradient elution procedures are described in Table 1 . The mass-spectrometry parameters were as follows: Electrospray Ionization ${ }^{+}$: capillary voltage, $4 \mathrm{kV}$; sampling cone, $35 \mathrm{kV}$; source temperature, $100^{\circ} \mathrm{C}$; desolvation temperature, $350^{\circ} \mathrm{C}$; cone gas flow, $50 \mathrm{l} / \mathrm{h}$; desolvation gas flow, $600 \mathrm{l} / \mathrm{h}$; extraction cone, $4 \mathrm{~V}$. Electrospray Ionization ${ }^{-}$: capillary voltage, $3.5 \mathrm{kV}$; sampling cone, $50 \mathrm{kV}$; source temperature, $100^{\circ} \mathrm{C}$; desolvation temperature, $350^{\circ} \mathrm{C}$; cone gas flow, $50 \mathrm{l} / \mathrm{h}$; desolvation gas flow, $700 \mathrm{l} / \mathrm{h}$; extraction cone, $4 \mathrm{~V}$. Scan time, 0.03 second; interscan time, 0.02 second; and scan range, $50-1000 \mathrm{~m} / \mathrm{z}$. Data analysis was performed using feature extraction and preprocessing with SIEVE software (Thermo, Sichuan, China), normalized, and edited into a two-dimensional data matrix using Excel 2010 software, including retention time, compound molecular weight, observations (samples), and peak intensity.

Statistical Methods. The data are presented as mean \pm S.D. SPSS 20.0 software (SPSS, Chicago, IL) was used to determine oneway analysis of variance with Fisher's protected least significant difference post hoc test to determine the significance of multiple comparisons. $P<0.05$ was considered statistically significant.

\section{Results}

Effect of JFNE and Fraction D on RAW264.7 Cell Viability by MTT Assay. Cells were cultivated with $5 \times 10^{-1}$ to $5 \times 10^{-5} \mathrm{mg} / \mathrm{ml} \mathrm{JFNE}$ and fraction D for 6 hours, none of which had a significant impact on RAW264.7 cell viability (Fig. 1). Therefore, LPS-induced RAW264.7 cells were treated with $\leq 0.5 \mathrm{mg} / \mathrm{ml}$ JFNE and fraction D for 3 hours in the subsequent experiments to determine the mechanism in which JFNE and fraction D exert their anti-inflammatory effects on LPS-induced RAW264.7 cells.

Effect of JFNE and Fraction $D$ on Secreted and mRNA Expression of NO, IL-6, IL-1 $\beta$, and TNF- $\alpha$ in RAW 264.7 Inflammatory Cells. As shown in Fig. 2, RAW264.7 cells incubated with $1 \mu \mathrm{g} / \mathrm{ml}$ LPS for 12 hours significantly increased the levels of NO, IL-6, IL- $1 \beta$, and TNF$\alpha$ in the cell culture supernatant, and the mRNA expression of iNOS, IL-6, IL-1 $\beta$, and TNF- $\alpha(P<0.01)$ relative to control, confirming the use of LPS-induced RAW264.7 cells as an efficient inflammatory model. Compared with untreated controls, RAW264.7 cells pretreated with 0.5 and $0.25 \mathrm{mg} / \mathrm{ml}$ JFNE and fraction D for 3 hours had significantly reduced levels of the NO, IL- $1 \beta$, and TNF- $\alpha$ in the cell culture supernatants, and fraction $D$ could also reduce the level of IL-6 $(P<0.05$ or $P<0.01)$. In addition, pretreatment with 0.5 and $0.25 \mathrm{mg} / \mathrm{ml} \mathrm{JFNE}$ and fraction D for 3 hours had significantly reduced the mRNA expression levels of iNOS, IL-6, IL-1 $\beta$, and TNF- $\alpha$ in RAW264.7 cells (Fig. 3). These results suggest that both JFNE and fraction D have antiinflammatory effects in LPS-stimulated RAW264.7 cells.

The Effect of JFNE and Fraction D on PI3K/AKT Signaling in LPS-Induced RAW264.7 Inflammatory Cells. Compared with the control group, RAW264.7 cells treated with $1 \mu \mathrm{g} / \mathrm{ml}$ LPS for 12 hours significantly increased the levels of phosphorylated PI3K and AKT proteins, suggesting that LPS stimulation can activate the PI3K/AKT signaling pathway. $0.5 \mathrm{mg} / \mathrm{ml}$ concentration of JFNE and fraction D significantly downregulated the expression levels of phosphorylated PI3K and AKT proteins in inflammatory cells $(P<0.05$ or $P<0.01)$. In addition, pretreated with $0.5 \mathrm{mg} / \mathrm{mL}$ and $0.25 \mathrm{mg} / \mathrm{mL}$ of JFNE and fraction $\mathrm{D}$ for $3 \mathrm{~h}$
TABLE 1

Gradient of mobile phase

\begin{tabular}{lccc}
\hline Time $(\mathrm{min})$ & Flow Rate $(\mathrm{ml} / \mathrm{min})$ & A $(\%)$ & B $(\%)$ \\
\hline 0 & 0.3 & 95 & 5 \\
1 & 0.3 & 95 & 5 \\
2 & 0.3 & 60 & 40 \\
7 & 0.3 & 20 & 80 \\
11 & 0.3 & 5 & 95 \\
15.5 & 0.3 & 95 & 5 \\
19.5 & 0.3 & 95 & 5 \\
\hline
\end{tabular}

had significantly reduced the mRNA expression levels of PI3K, AKT (Fig. 4), suggesting that the anti-inflammatory effects of JFNE and fraction D are regulated by the inhibition of PI3K/AKT signaling pathway activation (Fig. 4).

Exploring the Effect of JFNE and Fraction D on NF-кB Signaling Pathway by SN50. SN50 is a specific inhibitor of NF- $\kappa \mathrm{B}$ signaling pathway, and our results show that $40 \mu \mathrm{M}$ SN50 significantly reduces the levels of NO, IL- $1 \beta$, and TNF- $\alpha$ in the cell culture supernatant of RAW264.7 cells $(P<0.01$ or $P<0.05)$. This suggests that NF- $\kappa \mathrm{B}$ signaling is activated by LPS stimulation after 12 hours, and the upregulation of inflammatory factors (such as NO, IL- $1 \beta$, and TNF- $\alpha$ ) is associated with the activation of NF- $\kappa \mathrm{B}$ signaling pathway, as the levels of NO, IL- $1 \beta$, and TNF- $\alpha$ significantly decreased $(P<0.01)$ in the supernatant of the cells treated with JFNE and fraction D in combination with SN50. A more significant anti-inflammatory effect was observed in the cells coincubated with SN50 and JFNE or fraction D, compared with treatment with SN50 and JFNE or fraction D alone $(P<0.05$ or $P<0.01)$ (Fig. 5).

Regulatory Effect of JFNE and Fraction D on NF- $\mathrm{B} B$ Signaling and iNOS. The expression of iNOS, NF- $\kappa$ B (p50), and phosphorylated NF- $\kappa \mathrm{B}$ (p65) proteins in LPS-stimulated RAW264.7 cells significantly increased $(P<0.05)$ after LPS stimulation. A total of $0.5 \mathrm{mg} / \mathrm{ml}$ JFNE and fraction D significantly decreased the protein expression levels of iNOS, $\mathrm{NF}-\kappa \mathrm{B}$ (p50), and phosphorylated NF- $\kappa \mathrm{B}$ (p65) in LPSstimulated RAW264.7 cells $(P<0.05)$. In addition, the mRNA expression of iNOS, RELA, and NF- $\kappa$ B in response to LPS treatment significantly increased $(P<0.05)$, whereas the mRNA expression of CHUK decreased $(P<0.05)$. A quantity amounting to $0.5 \mathrm{mg} / \mathrm{ml}$ JFNE and fraction D significantly decreased the expression of iNOS, RELA, CHUK, and NF- $\kappa \mathrm{B}$ mRNA expression in RAW264.7 inflammatory cells $(P<0.05)$, whereas the expression of CHUK increased, relative to control (Fig. 6).

Main Chemical Components of Fraction D. LC-MS analysis of fraction D identified 201 compounds, with high concentrations of betaine and triphenylphosphine oxide. The relative percentages of the top 20 compounds are shown in Table 2.

\section{Discussion}

Previous studies have shown that Jing-Fang power has specific anti-inflammatory properties (Liu et al., 2007, 2013; Changtian et al., 2016), and that extracts of JFNE retain these anti-inflammatory effects. In this study, JFNE was separated by silica gel column chromatography to explore the properties of the active anti-inflammatory compounds in JFNE. Previous 

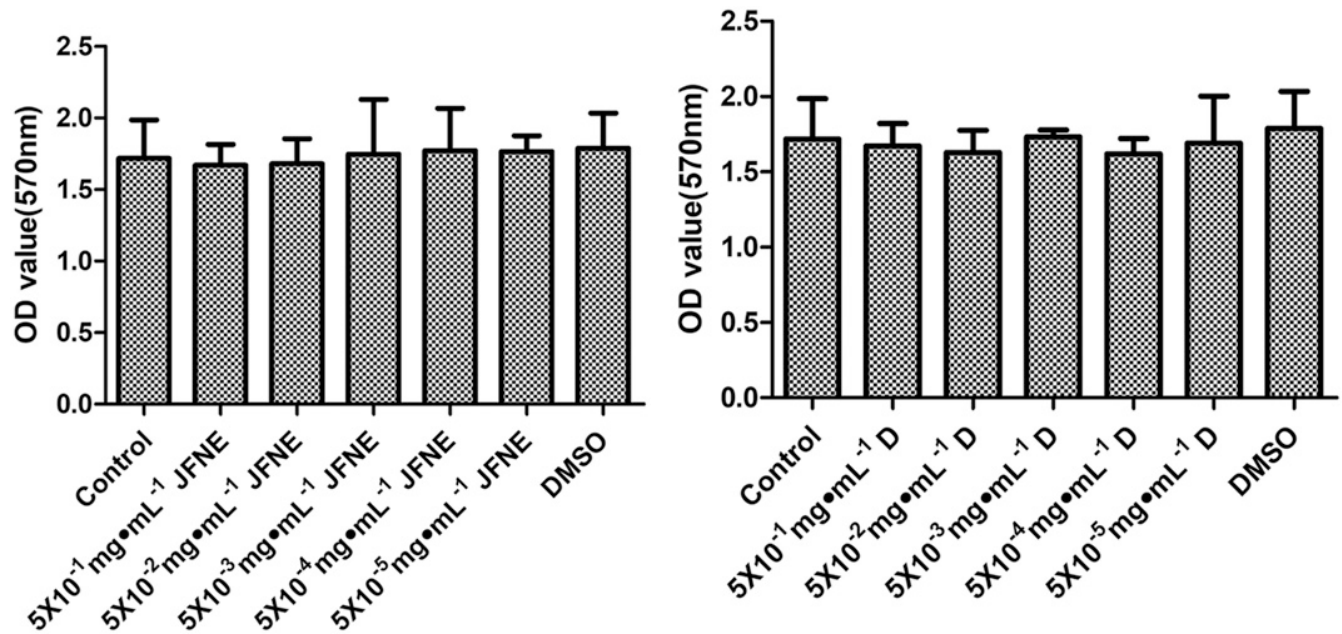

Fig. 1. The effect of JFNE and fraction D on RAW264.7 cell viability. Cells were cultivated with $5 \times 10^{-1}$ to $5 \times 10^{-5} \mathrm{mg} / \mathrm{ml} \mathrm{JFNE}$ and fraction D for 6 hours, and then $100 \mu \mathrm{l}$ MTT was added to observe the effect of each drug on cell viability by measuring the optical density value at $490 \mathrm{~nm}$. Data are presented as the mean \pm S.E.M.; $n=6$.

in vivo experiments in mice demonstrated that the isolated fraction D significantly inhibited inflammation and swelling of the auricle induced by p-xylene and inhibited the rate of swelling by nearly $71.96 \%$, suggesting that fraction $\mathrm{D}$ isolated from JFNE is anti-inflammatory. In this study, the LPSinduced RAW264.7 macrophage inflammatory model was used to explore the mechanism by which JFNE and fraction D exert their anti-inflammatory effects. We found that the specific anti-inflammatory properties of JFNE and fraction D were associated with the inhibition of PI3K/AKT and NF- $\kappa$ B signaling. In addition, fraction D isolated from JFNE was equally as effective as JFNE.

RAW264.7 is a mouse-derived mononuclear macrophage cell line, and LPS stimulation of RAW264.7 cells can induce classic M1 activation (Van Dyken and Locksley, 2013; Zhu et al., 2015). M1 macrophages are characterized by

\section{Fraction D}
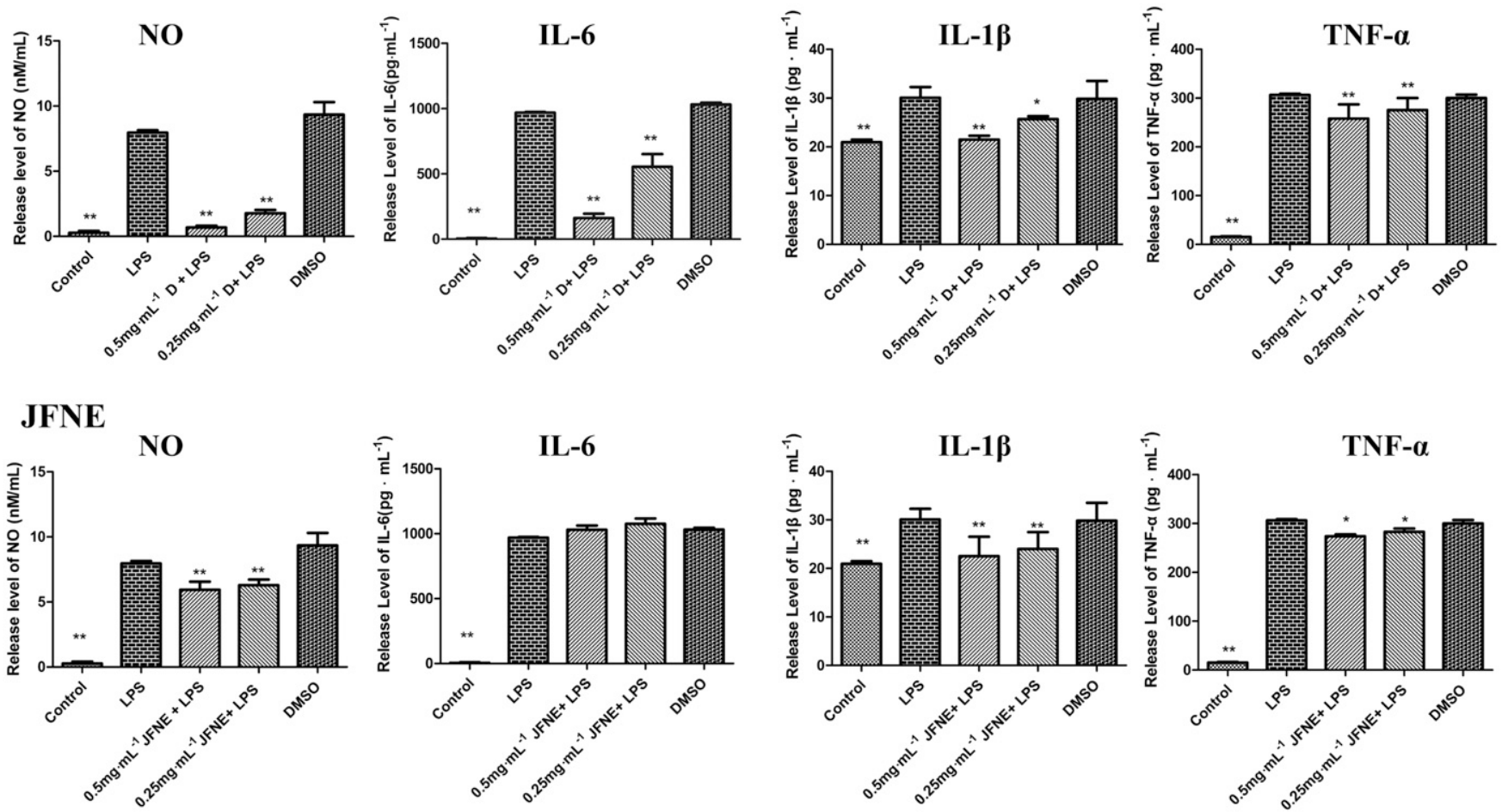

Fig. 2. Effect of JFNE and fraction D on NO, IL-6, IL-1 $\beta$, and TNF- $\alpha$ in supernatant of LPS-induced RAW264.7 cells. RAW264.7 cells were stimulated with $1 \mu \mathrm{g} / \mathrm{ml}$ LPS for 12 hours (LPS) and pretreated with fraction D (fraction D + LPS), JFNE (JFNE + LPS), and the same volume of DMEM with $0.25 \%$ DMSO (DMSO) for 3 hours before LPS was added; the blank control group contained an equal volume of DMEM (Control), the cell culture supernatant was collected, and the protein levels of NO, IL-6, IL-1 $\beta$, and TNF- $\alpha$ were assayed. Data are presented as the mean \pm S.E.M., compared with LPS-only control cells; $* P<0.05 ; * * P<0.01 ; n=6$. 

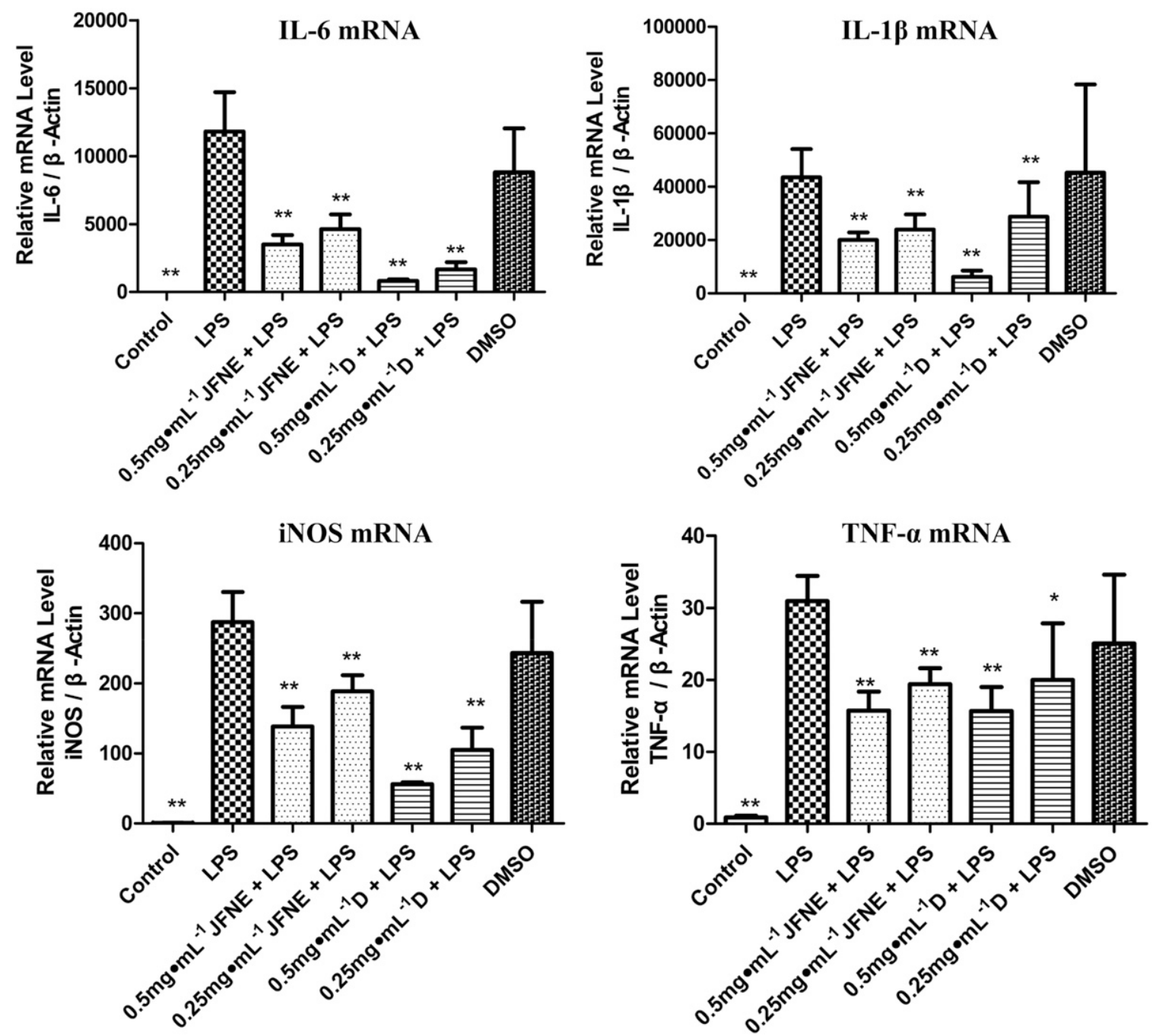

Fig. 3. Effect of JFNE and fraction D on mRNA expression of iNOS, IL-6, IL-1 $\beta$, and TNF- $\alpha$ in LPS-induced RAW264.7 cells. RAW264.7 cells were stimulated with $1 \mu \mathrm{g} / \mathrm{ml}$ LPS for 12 hours (LPS) and pretreated with fraction D (fraction D + LPS), JFNE (JFNE + LPS), and the same volume of DMEM with $0.25 \%$ DMSO (DMSO) for 3 hours before LPS was added; the blank control group contained an equal volume of DMEM (Control); and the fold change in gene expression was normalized to $\beta$-actin expression. The changes in gene expression were calculated using $2^{-\Delta \Delta \mathrm{Ct}}$. Data are presented as the mean \pm S.E.M., compared with LPS-only control cells; $* P<0.05 ; * * P<0.01(n=4)$.

the production of high concentrations of proinflammatory factors, including IL-1 $\beta$, IL-6, IL-12, TNF- $\alpha$, and iNOS; and M1-type macrophage-mediated iNOS synthesizes NO through the L-arginine pathway, which plays a key role in promoting the inflammatory response (Kröncke et al., 1995). In addition, macrophages are known to recruit adaptive immune cells such as T-lymphocytes to neutralize intracellular pathogens by generating reactive oxygen species and nitrogen free radicals and secreting a plethora of inflammatory cytokines to promote an inflammatory response (Nathan and Shiloh, 2000), as part of the bacterial infection-type inflammatory responses (Holden et al., 2014). Therefore, the LPS-induced RAW264.7 cell inflammatory model is widely used in anti-inflammatory studies in vitro. We show that JFNE and fraction D significantly reduce the mRNA expression and levels of secreted NO, IL-6, IL- $1 \beta$, and TNF- $\alpha$ in LPS-induced RAW264.7 inflammatory cells. These results suggest that both JFNE and fraction D have antiinflammatory effects and that the anti-inflammatory effect of fraction D was comparable to that of JFNE.
The PI3K/AKT pathway is a typical intracellular signaling pathway, and studies have shown that PI3K/AKT signaling is involved in the inflammatory response and can be activated by cell membrane receptor binding. This activation produces phosphatidylinositol-3,4,5-triphosphate and further activates downstream signaling proteins, including AKT (Pritchard et al., 2016; Sun et al., 2017). The AKT is a key member of the family of survival after cell injury proteins (Krasilnikov, 2000). Activated AKT subsequently dissociates from the membrane and binds to target sites in the cytoplasm and nucleus that plays a key role in numerous biologic responses by phosphorylating a range of intracellular proteins. Recent studies have shown that the PI3K/AKT pathway is necessary for the regulation of acute inflammatory responses in vivo and in vitro by regulating the activation of the NF- $\kappa$ B pathway via nuclear translocation of NF- $\kappa \mathrm{B}$ key proteins (such as NF- $\kappa \mathrm{B}$ p50 and RELA p65) (Iyer et al., 2011; Liu et al., 2017). In this study, the effects of JFNE and fraction D on the PI3K and AKT total protein and phosphorylation levels in RAW264.7 cells were observed by Western blot. LPS stimulation significantly 


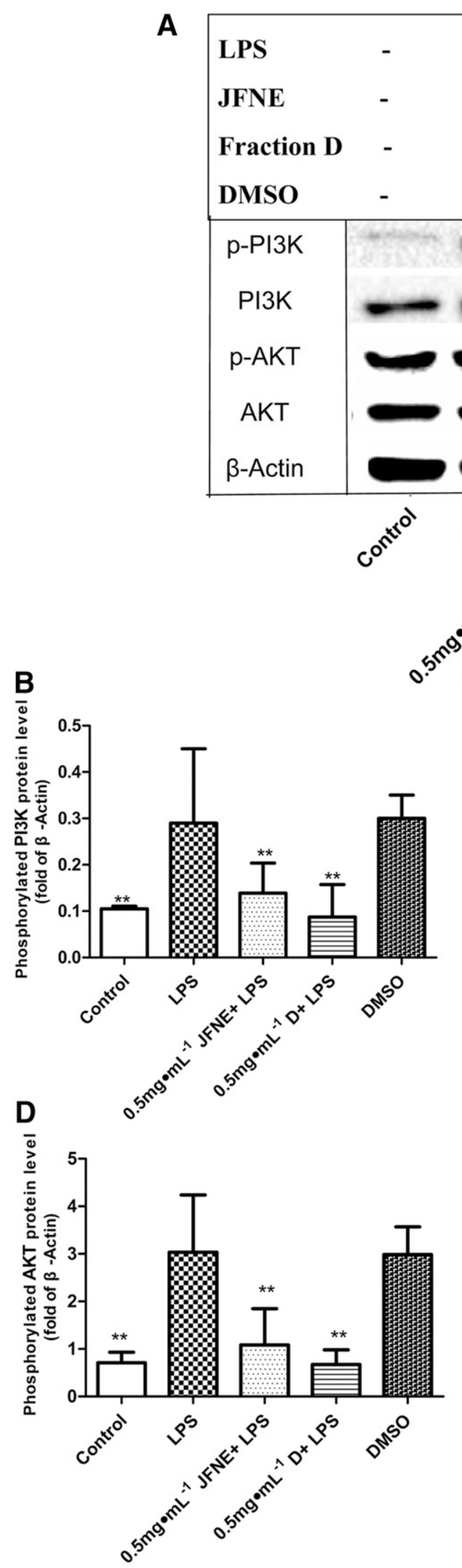

Fig. 4. The effect of JFNE and fraction D on the phosphorylation and mRNA expression levels of PI3K and AKT. (A) After RAW264.7 cells were pretreated with fraction D (fraction D + LPS) or JFNE (JFNE + LPS) and stimulated with $1 \mu \mathrm{g} / \mathrm{ml}$ LPS for 12 hours (LPS), the phosphorylation and total protein levels of PI3K and AKT were assayed by Western blot. (B) Phosphorylation of PI3K was calculated as the ratio of phosphorylated PI3K (p-PI3K) to total PI3K. (C) The mRNA expression of PI3K was measured by reverse-transcription polymerase chain reaction. (D) Phosphorylation of AKT was calculated as the ratio of phosphorylated AKT (p-PI3K) to total AKT. (E) The mRNA expression of AKT was measured by reverse-transcription polymerase chain reaction. Data are presented as the mean \pm S.E.M., compared with LPS-only control cells; $* P<0.05$; $* * P<0.01(n=4)$.

E

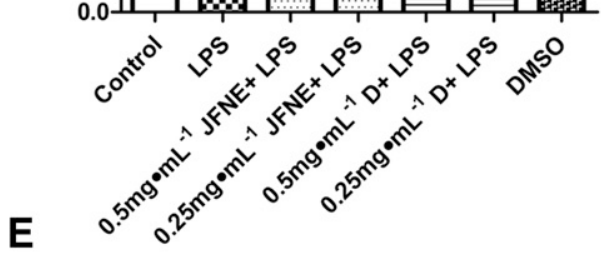

increased the phosphorylation and mRNA expression levels of PI3K and AKT in RAW264.7 cells, which were reduced in response to both JFNE and fraction D treatment.
In addition, JFNE and fraction D treatment significantly downregulates the activation of the PI3K/AKT signaling pathway. SN50, a specific inhibitor of NF- $\kappa$ B signaling, was 


\section{JFNE}
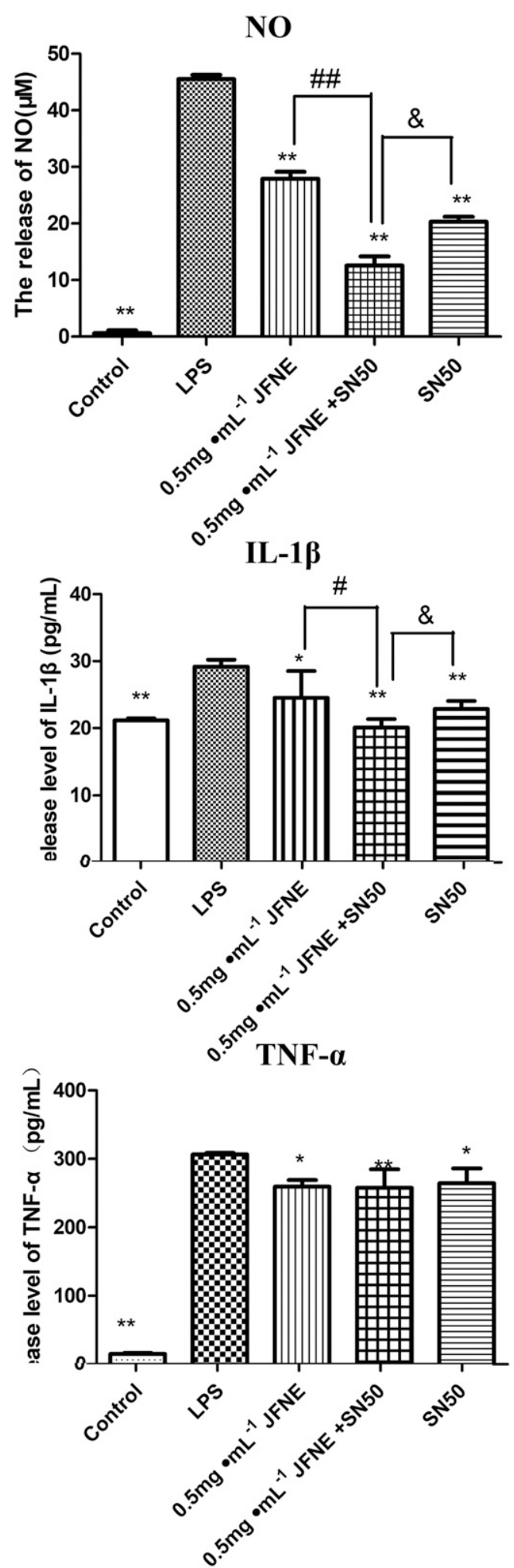

Fraction D
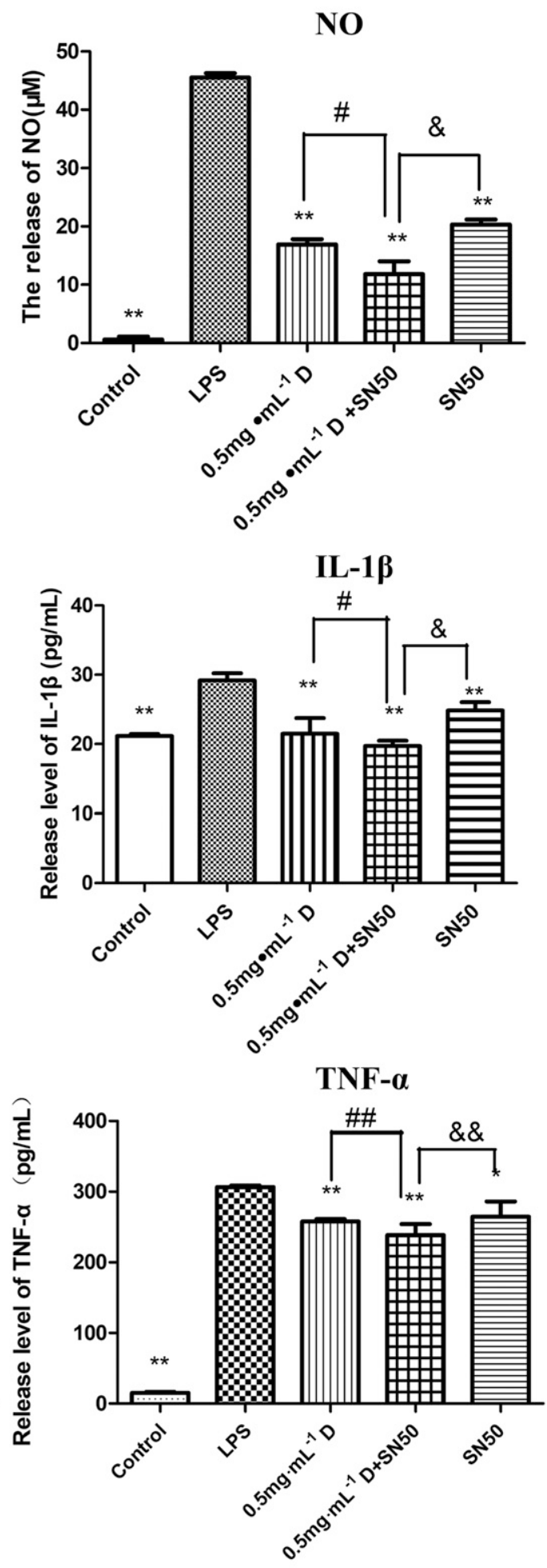

Fig. 5. The effect of JFNE and fraction $D$ treatment combined with NF- $\kappa$ B pathway specific inhibitor SN50 on the expression of NO, IL-1 $\beta$, and TNF- $\alpha$ in the supernatant of RAW264.7 cell cultures induced by LPS. SN50 $(40 \mu \mathrm{M})$, an inhibitor of NF- $\kappa$ B signaling, was added 1 hour before treatment with JFNE and fraction D; the cell culture supernatant was collected; and levels of NO, IL-1 $\beta$, and TNF- $\alpha$ were assayed. Compared with the LPS group, ${ }^{*} P<0.05$; ${ }^{* *} P<0.01$. Compared with JFNE and fraction D treatment alone, ${ }^{\#} P<0.05$; ${ }^{\#} P<0.01$. Compared with treatment with SN50 alone, ${ }^{\&} P<0.05 ; \& P<0.01$. 
A

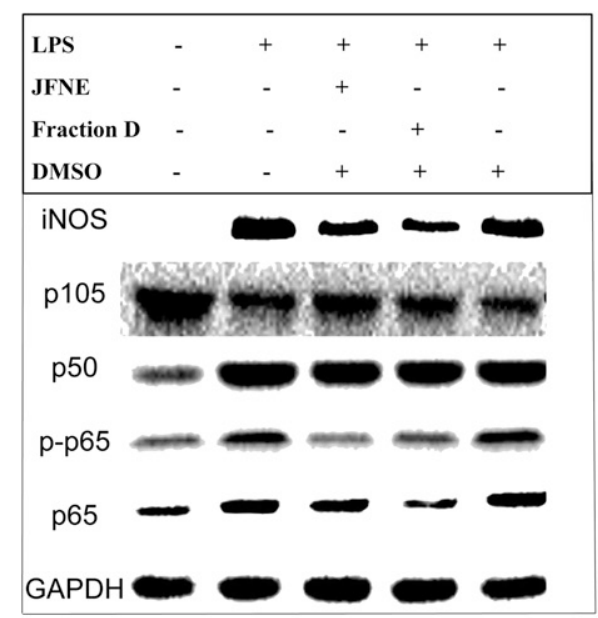

B

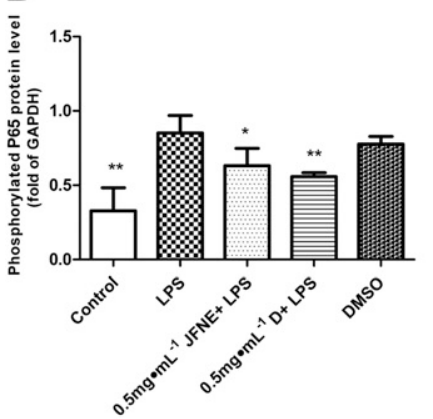

D

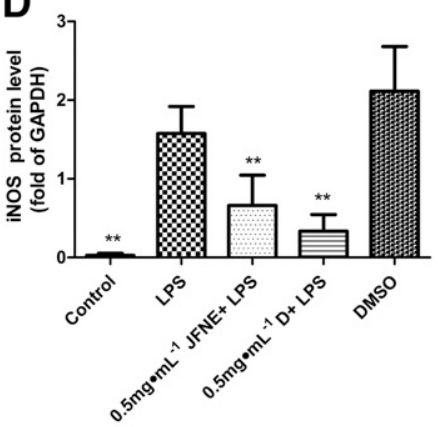

$\mathbf{F}$

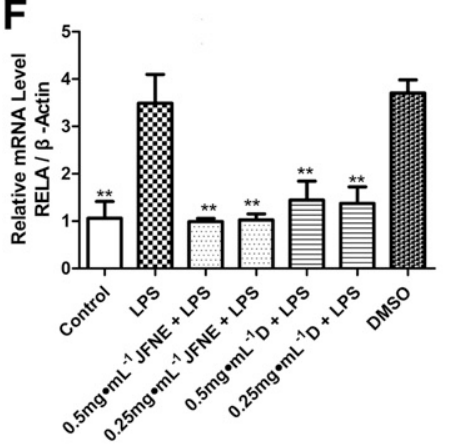

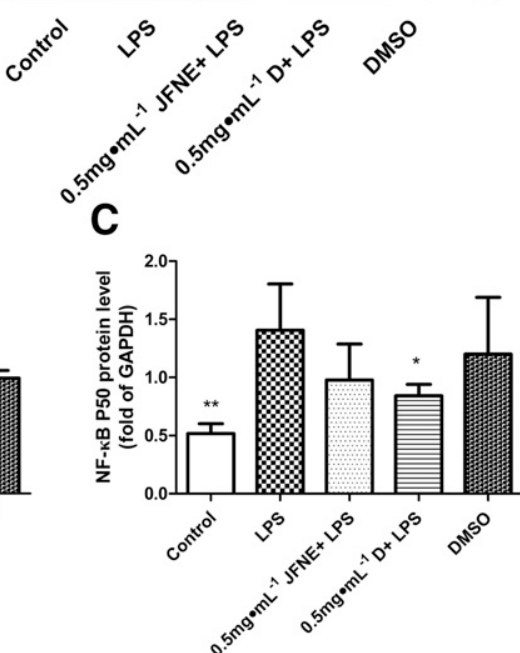

E

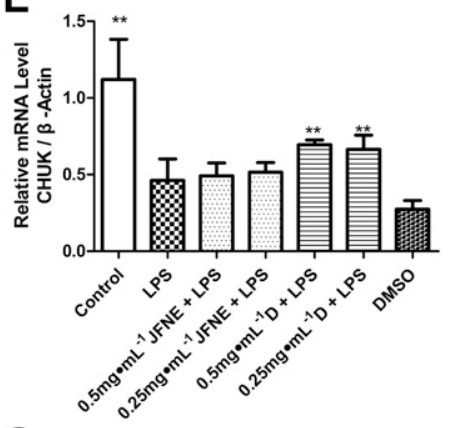

G

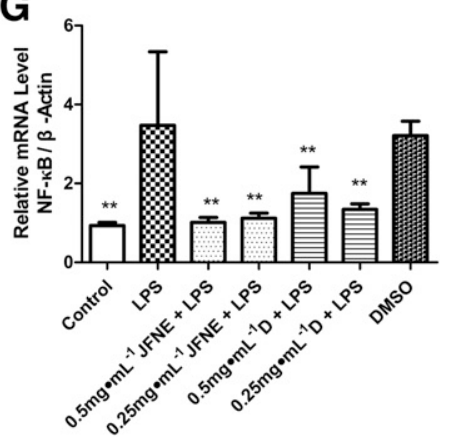

Fig. 6. Effect of JFNE and fraction D on protein levels of p-p65, p65, p50, p105, iNOS, and mRNA expression of CHUK, RELA, and NF- $\kappa$ B in LPS-induced RAW264.7 inflammatory cells. (A) After RAW264.7 cells were pretreated with fraction D (fraction D + LPS) and JFNE (JFNE + LPS) and stimulated with $1 \mu \mathrm{g} / \mathrm{ml}$ LPS for 12 hours (LPS), the phosphorylation and protein levels of iNOS, NF- $\kappa \mathrm{B}$ p65 (p65), phosphorylated NF- $\kappa$ B p65 (p-p65), NF- $\kappa$ B p50 (p50), and NF- $\kappa$ B p105 (p105) were assayed by Western blotting. (B) The phosphorylation of p65 was calculated as the ratio of p-p65 to glyceraldehyde-3phosphate dehydrogenase. (C) The level of p50 was calculated as the ratio of p60 to glyceraldehyde-3-phosphate dehydrogenase. (D) The protein level of iNOS was calculated as the ratio of iNOS to glyceraldehyde-3-phosphate dehydrogenase. The mRNA expression levels of (E) CHUK, (F) RELA, and (G) NF- $\kappa$ B were measured by reverse-transcription polymerase chain reaction. Data are presented as the mean \pm S.E.M., compared with LPS-only control cells; ${ }^{*} P<0.05$; $* * P<0.01(n=4)$. added to RAW264.7 cells 1 hour before LPS stimulation to determine whether the $\mathrm{NF}-\kappa \mathrm{B}$ signaling pathway was involved in the LPS-induced RAW264.7 cell inflammatory response and to observe whether the anti-inflammatory effect of JFNE and fraction D was related to the inhibition of $\mathrm{NF}-\kappa \mathrm{B}$ signaling pathway. The results showed that $40 \mu \mathrm{M}$ 
TABLE 2

Main chemical components of fraction D by LC-MS

\begin{tabular}{|c|c|c|c|c|c|}
\hline No. & Name & Molecular & Formula & Retention time (min) & Percentage $(\%)$ \\
\hline 1 & Betaine & 117.08 & $\mathrm{C}_{5} \mathrm{H}_{11} \mathrm{NO}_{2}$ & 1.38 & 12.57 \\
\hline 2 & Triphenylphosphine oxide & 278.08 & $\mathrm{C}_{18} \mathrm{H}_{15} \mathrm{OP}$ & 5.82 & 5.63 \\
\hline 3 & Choline & 103.10 & $\mathrm{C}_{5} \mathrm{H}_{13} \mathrm{NO}$ & 1.34 & 4.86 \\
\hline 4 & 1-Linoleoyl-sn-glycero-3-phosphocholine & 519.33 & $\mathrm{C}_{26} \mathrm{H}_{50} \mathrm{NO}_{7} \mathrm{P}$ & 6.92 & 4.73 \\
\hline 5 & DL-Stachydrine & 143.09 & $\mathrm{C}_{7} \mathrm{H}_{13} \mathrm{NO}_{2}$ & 1.42 & 3.64 \\
\hline 6 & O-glutaroyl-L-carnitine & 275.14 & $\mathrm{C}_{12} \mathrm{H}_{21} \mathrm{NO}_{6}$ & 1.42 & 2.95 \\
\hline 7 & $\begin{array}{l}\text { O-ureido-l-serine } \\
\text { (2S)-4-methyl-2-(\{[(3S,4S,5R)-2,3,4- trihydroxy-5- } \\
\text { (hydroxymethyl)tetrahydro- }\end{array}$ & 163.06 & $\mathrm{C}_{4} \mathrm{H}_{9} \mathrm{~N}_{3} \mathrm{O}_{4}$ & 1.14 & 2.39 \\
\hline 8 & 2-furanyl]methyl\}amino)pentanoic acid (nonpreferred name) & 293.15 & $\mathrm{C}_{12} \mathrm{H}_{23} \mathrm{NO}_{7}$ & 2.08 & 2.35 \\
\hline 9 & Dibutyl phthalate & 278.15 & $\mathrm{C}_{16} \mathrm{H}_{22} \mathrm{O}_{4}$ & 8.14 & 2.35 \\
\hline 10 & O-3-methylglutarylcarnitine & 289.15 & $\mathrm{C}_{13} \mathrm{H}_{23} \mathrm{NO}_{6}$ & 1.49 & 1.78 \\
\hline 11 & Adenosine & 267.10 & $\mathrm{C}_{10} \mathrm{H}_{13} \mathrm{~N}_{5} \mathrm{O}_{4}$ & 2.04 & 1.71 \\
\hline 12 & 1-Oleoylglycerone 3-phosphate & 434.24 & $\mathrm{C}_{21} \mathrm{H}_{39} \mathrm{O}_{7} \mathrm{P}$ & 9.05 & 1.37 \\
\hline 13 & 1-Hexadecanoyl-sn-glycero-3-phosphocholine & 495.33 & $\mathrm{C}_{24} \mathrm{H}_{50} \mathrm{NO}_{7} \mathrm{P}$ & 7.32 & 1.36 \\
\hline 14 & Leonurine & 311.15 & $\mathrm{C}_{14} \mathrm{H}_{21} \mathrm{~N}_{3} \mathrm{O}_{5}$ & 4.34 & 1.23 \\
\hline 15 & Adenine & 135.05 & $\mathrm{C}_{5} \mathrm{H}_{5} \mathrm{~N}_{5}$ & 1.48 & 1.11 \\
\hline 16 & Stearamide & 283.29 & $\mathrm{C}_{18} \mathrm{H}_{37} \mathrm{NO}$ & 11.32 & 1.06 \\
\hline 17 & Oleoyl-lysophosphatidylcholine & 521.35 & $\mathrm{C}_{26} \mathrm{H}_{52} \mathrm{NO}_{7} \mathrm{P}$ & 7.61 & 1.01 \\
\hline 18 & 1-Aminocyclohexanecarboxylic acid & 143.09 & $\mathrm{C}_{7} \mathrm{H}_{13} \mathrm{NO}_{2}$ & 2.06 & 0.98 \\
\hline 19 & 4-Undecylbenzenesulfonic acid & 312.18 & $\mathrm{C}_{17} \mathrm{H}_{28} \mathrm{O}_{3} \mathrm{~S}$ & 10.66 & 0.89 \\
\hline 20 & 1-Palmitoyl lysophosphatidic acid & 410.24 & $\mathrm{C}_{19} \mathrm{H}_{39} \mathrm{O}_{7} \mathrm{P}$ & 10.52 & 0.75 \\
\hline
\end{tabular}

SN50 significantly reduced the levels of NO, IL- $1 \beta$, and $\mathrm{TNF}-\alpha$ in cell culture supernatants, suggesting that NF- $\kappa \mathrm{B}$ signaling was activated and elevated levels of inflammatory factors (such as NO, IL- $1 \beta$, and TNF- $\alpha$ ) are associated with activation of the NF- $\kappa \mathrm{B}$ signaling pathway. Additionally, the results of combined JFNE or fraction D treatment with SN50 show that the anti-inflammatory effect of JFNE and fraction $\mathrm{D}$ is related to the inhibition of the NF- $\kappa \mathrm{B}$ signaling pathway.

Western blot analysis determined that JFNE and fraction D significantly decreased the protein levels of NF- $\kappa \mathrm{B}$ (p50), phosphorylated NF- $\kappa \mathrm{B}$ (p65), and iNOS in LPS-stimulated RAW264.7 cells. Moreover, JFNE and fraction D significantly decreased the mRNA expression of iNOS, RELA, and NF- $\kappa$ B and increased the mRNA expression of CHUK in RAW264.7 inflammatory cells. These results suggested that the antiinflammatory effect of JFNE and fraction D is associated with inhibition of the NF- $\kappa \mathrm{B}$ pathway.

In view of the anti-inflammatory properties of fraction D, LC-MS combined with compound discovery software by mzcloud, chemspider, and Masslist database was used to analyze and identify the molecular components of fraction D. LC-MS analysis found 216 components consisting of high levels of betaine, triphenylphosphine oxide, choline, 1-linoleoyl-sn-glycero-3-phosphocholine, and Dl-Stachydrine in fraction D. A search of related literature for betaine, triphenylphosphine oxide, choline, 1-linoleoyl-sn-glycero-3phosphocholine, and Dl-Stachydrine revealed a great number of anti-inflammation studies on betaine and choline; however, very little data discovered on triphenylphosphine oxide, 1-linoleoyl-sn-glycero-3-phosphocholine, and Dl-Stachydrine exist. Betaine has anti-inflammatory and antioxidative properties (Hagar et al., 2015; Zhao et al., 2018). Mechanistically, betaine exerts its antioxidative effects by maintaining thiol levels, particularly glutathione levels, to inhibit reactive oxygen species production (Cholewa et al., 2014), primarily by ameliorating sulfur amino acid metabolism (Craig, 2004). In addition, Kharbanda et al. (2012) found that betaine prevents NO synthase 2 expression, a process initiated by inflammation. Furthermore, betaine also inhibits the activity of some upstream signaling molecules that induce the activation of NF- $\kappa$ B (Kim et al., 2014). Betaine reduces endogenous damage-associated molecular pattern generation to inhibit the NF- $\kappa \mathrm{B}$ pathway (Zhang et al., 2013). This study showed that betaine exerts an anti-inflammatory effect via inhibition of NF- $\kappa$ B signaling and is an antioxidant, consistent with our findings. Additionally, the antiinflammatory effects of betaine are related to the inhibition of Pyrin Domain Containing Protein 3 (NLRP3) inflammasome activation, regulation of energy metabolism, and the mitigation of endoplasmic reticulum stress and apoptosis (Zhao et al., 2018). Recent studies have determined that choline plays an important role in macrophage phospholipid metabolism and the inflammatory response (Snider et al., 2018), and Pan and Wang (2014) found that combined choline and aspirin therapy synergistically attenuated an acute inflammatory response. Besides, Parrish et al. (2008) found that choline suppressed TNF release from endotoxin-activated human whole blood and macrophages, which characterize the anti-inflammatory efficacy of choline and demonstrate that the modulation of TNF release by choline was associated with significant inhibition of $\mathrm{NF}-\kappa \mathrm{B}$ activation and requires $\alpha 7$ nicotinic acetylcholine receptor-mediated signaling. Their follow-up studies further confirmed the close relationship between $\alpha 7$ nicotinic acetylcholine receptor signaling and inflammatory response (Silverman et al., 2015; Yang et al., 2019). In summary, betaine and choline may be the main components of fraction D responsible for the anti-inflammatory properties observed.

In conclusion, JFNE and fraction $\mathrm{D}$ have antiinflammatory effects in LPS-induced RAW264.7 cells, which may be due to the inhibition of PI3K/AKT signaling and the regulation of $\mathrm{NF}-\kappa \mathrm{B}$ pathway activation; however, this antiinflammatory effect requires further verification in vivo.

\section{Authorship Contributions}

Participated in research design: Rao, Zeng.

Conducted experiments: Rao, Cao.

Contributed new reagents or analytic tools: Luo. 
Performed data analysis: Shi, Liu.

Wrote or contributed to the writing of the manuscript: Rao, Cao.

\section{References}

Brown JS and Banerji U (2017) Maximising the potential of Akt inhibitors as anticancer treatments. Pharmacol Ther 172:101-115.

Burke JE and Williams RL (2015) Synergy in activating class I PI3Ks. Trends Biochem Sci 40:88-100.

Changtian Q, Zhe W, Taoqun W, Feng W, Xi X, and Zhi Z (2016) Study on the mechanism of antiallergic effect of ethyl acetate extraction of jingfang powder in allergic animal models. Pharm Clin Chin Materia Medica 32 (01):127-130

Cholewa JM, Guimarães-Ferreira L, and Zanchi NE (2014) Effects of betaine on performance and body composition: a review of recent findings and potential mechanisms. Amino Acids 46:1785-1793.

Craig SA (2004) Betaine in human nutrition. Am J Clin Nutr 80:539-549.

Hagar H, Medany AE, Salam R, Medany GE, and Nayal OA (2015) Betaine supplementation mitigates cisplatin-induced nephrotoxicity by abrogation of oxidative/nitrosative stress and suppression of inflammation and apoptosis in rats. Exp Toxicol Pathol 67:133-141.

Holden JA, Attard TJ, Laughton KM, Mansell A, O’Brien-Simpson NM, and Reynolds EC (2014) Porphyromonas gingivalis lipopolysaccharide weakly activates M1 and M2 polarized mouse macrophages but induces inflammatory cytokines. Infect Immun 82:4190-4203.

Iyer AK, Azad N, Talbot S, Stehlik C, Lu B, Wang L, and Rojanasakul Y (2011) Antioxidant c-FLIP inhibits Fas ligand-induced NF-kappaB activation in a phosphatidylinositol 3-kinase/Akt-dependent manner. J Immunol 187:3256-3266.

Johnston LK, Rims CR, Gill SE, McGuire JK, and Manicone AM (2012) Pulmonary macrophage subpopulations in the induction and resolution of acute lung injury. Am J Respir Cell Mol Biol 47:417-426.

Kharbanda KK, Todero SL, King AL, Osna NA, McVicker BL, Tuma DJ, Wisecarver JL, and Bailey SM (2012) Betaine treatment attenuates chronic ethanol-induced hepatic steatosis and alterations to the mitochondrial respiratory chain proteome. Int $J$ Hepatol 2012:962183.

Kim DH, Sung B, Chung HY, and Kim ND (2014) Modulation of colitis-associated colon tumorigenesis by baicalein and betaine. J Cancer Prev 19:153-160.

Krasilnikov MA (2000) Phosphatidylinositol-3 kinase dependent pathways: the role in control of cell growth, survival, and malignant transformation. Biochemistry (Mosc) 65:59-67.

Kröncke KD, Fehsel K, and Kolb-Bachofen V (1995) Inducible nitric oxide synthase and its product nitric oxide, a small molecule with complex biological activities Biol Chem Hoppe Seyler 376:327-343.

Liu S, Li X, Wu Y, Duan R, Zhang J, Du F, Zhang Q, Li Y, and Li N (2017) Effects of vaspin on pancreatic $\beta$ cell secretion via PI3K/Akt and NF-kB signaling pathways. PLoS One 12:e189722.

Liu X, Zeng N, and Zhao L (2007) Experimental study on anti-inflammatory and antiallergic effects of JingFang powder. Pharm Clin Chin Materia Medica 23:158.

Liu Y, Zhe W, Xiping G, Jing Y, Zhiqiang W, and Min H (2013) The protective effect of jingfang powder's effective extract of anti-inflammatory action on lipopolysaccharide-induced acute lung injury in mice. Pharm Clin Chin Materia Medica 29(03):139-142.

Matthay MA, Ware LB, and Zimmerman GA (2012) The acute respiratory distress syndrome. J Clin Invest 122:2731-2740.

Nathan C and Shiloh MU (2000) Reactive oxygen and nitrogen intermediates in the relationship between mammalian hosts and microbial pathogens. Proc Natl Acad Sci USA 97:8841-8848.

Nguyen DP, Li J, Yadav SS, and Tewari AK (2014) Recent insights into NF-кB signalling pathways and the link between inflammation and prostate cancer. $B J U$ Int 114:168-176.
Pan ZY and Wang H (2014) Synergistic interaction between choline and aspirin against acute inflammation induced by carrageenan and lipopolysaccharide. Int Immunopharmacol 20:229-237.

Parrish WR, Rosas-Ballina M, Gallowitsch-Puerta M, Ochani M, Ochani K, Yang LH, Hudson L, Lin X, Patel N, Johnson SM, et al. (2008) Modulation of TNF release by choline requires $\alpha 7$ subunit nicotinic acetylcholine receptor-mediated signaling. Mol Med 14:567-574.

Pritchard RA, Falk L, Larsson M, Leinders M, and Sorkin LS (2016) Different phosphoinositide 3-kinase isoforms mediate carrageenan nociception and inflammation. Pain 157:137-146.

Routray I and Ali S (2016) Boron induces lymphocyte proliferation and modulates the priming effects of lipopolysaccharide on macrophages. PLoS One 11:e0150607.

Shi ZM, Han YW, Han XH, Zhang K, Chang YN, Hu ZM, Qi HX, Ting C, Zhen Z, and Hong W (2016) Upstream regulators and downstream effectors of NF-кB in Alzheimer's disease. J Neurol Sci 366:127-134.

Silverman HA, Dancho M, Regnier-Golanov A, Nasim M, Ochani M, Olofsson PS, Ahmed M, Miller EJ, Chavan SS, Golanov E, et al. (2015) Brain region-specific alterations in the gene expression of cytokines, immune cell markers and cholinergic system components during peripheral endotoxin-induced inflammation. Mol Med 20:601-611.

Snider SA, Margison KD, Ghorbani P, LeBlond ND, O'Dwyer C, Nunes JRC, Nguyen $\mathrm{T}, \mathrm{Xu} \mathrm{H}$, Bennett SAL, and Fullerton MD (2018) Choline transport links macrophage phospholipid metabolism and inflammation. J Biol Chem 293:11600-11611.

Sun H, Zhu X, Cai W, and Qiu L (2017) Hypaphorine attenuates lipopolysaccharideinduced endothelial inflammation via regulation of TLR4 and PPAR- $\gamma$ dependent on PI3K/Akt/mTOR signal pathway. Int J Mol Sci 18:844.

Takemura Y, Iwasaki Y, Nagata K, Yokomura I, Tando S, Fushiki S, and Matsubara $\mathrm{H}$ (2005) Influence of depletion of alveolar macrophages on apoptosis in Candidainduced acute lung injury. Exp Lung Res 31:307-321.

Van Dyken SJ and Locksley RM (2013) Interleukin-4- and interleukin-13-mediated alternatively activated macrophages: roles in homeostasis and disease. Annu Rev Immunol 31:317-343.

Yang H, Liu H, Zeng Q, Imperato GH, Addorisio ME, Li J, He M, Cheng KF, Al-Abed Y, Harris HE, et al. (2019) Inhibition of HMGB1/RAGE-mediated endocytosis by HMGB1 antagonist box A, anti-HMGB1 antibodies, and cholinergic agonists suppresses inflammation. Mol Med 25:13.

Yu L, Wang Z, Xiong R, Gong X, Gou L, Tang Q, Shen C, and Zeng N (2013) Experimental study on the primary screening of effective parts of Jing Fang San with anti-inflammatory and anti-allergic effects. Lishizhen Med Mater Med Res 24 271-273.

Zhang H, Shan Y, Wu Y, Xu C, Yu X, Zhao J, Yan J, and Shang W (2017) Berberine suppresses LPS-induced inflammation through modulating Sirt1/NF-кB signaling pathway in RAW264.7 cells. Int Immunopharmacol 52:93-100.

Zhang W, Wang LW, Wang LK, Li X, Zhang H, Luo LP, Song JC, and Gong ZJ (2013) Betaine protects against high-fat-diet-induced liver injury by inhibition of highmobility group box 1 and Toll-like receptor 4 expression in rats. Dig Dis Sci 58(11): 3198-3206.

Zhao G, He F, Wu C, Li P, Li N, Deng J, Zhu G, Ren W, and Peng Y (2018) Betaine in inflammation: mechanistic aspects and applications. Front Immunol 9:1070.

Zhe W, Liu Y, Xiping G, Jing Y, Min H, Zhiqiang W, Xing P, Xue W, and Nan Z (2013) The anti-allergic effects of ethyl acetate extract of jingfang powder. Pharm Clin Chin Materia Medica 29:92-95.

Zhu L, Zhao Q, Yang T, Ding W, and Zhao Y (2015) Cellular metabolism and macrophage functional polarization. Int Rev Immunol 34:82-100.

Address correspondence to: Dr. Nan Zeng, Department of Pharmacology, College of Pharmacy, Chengdu University of TCM, 1166, Wenjiang District, Chengdu City, Sichuan Province, Chengdu 611137, PR China. E-mail: 19932015@cdutcm.edu.cn 